\title{
Uso de Livro-Texto Como Suporte nas Disciplinas de Cursos Universitários
}

\author{
Use of Schoolbooks as Support in Disciplines of the University Courses
}

\author{
Alessandro Costa da Silva*a; Marcos Eduardo Miranda Santos ${ }^{\mathrm{b}}$ \\ ${ }^{a}$ Universidade Estadual do Maranhão, Departamento de Química e Biologia. MA, Brasil.

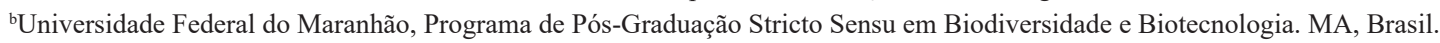 \\ *E-mail: alessandro@uema.br.
}

\begin{abstract}
Resumo
Embora haja livros didáticos nas bibliotecas como material de apoio para as disciplinas, tem-se a necessidade de mostrar aos estudantes as especificidades da região na qual vivem, visto que muitos desses livros são exógenos. Diante do exposto, o livro-texto Química Ambiental: uma abordagem introdutória e generalista, foi uma tentativa de encontrar um material didático que além de incluir assuntos da disciplina, apresentasse exemplos locais. Foram entrevistados estudantes, que revelaram que a utilização do livro-texto, além de uma ferramenta de apoio no decorrer da disciplina, também desempenhou um importante papel no processo de sua formação profissional e como cidadãos conscientes e atuantes no espaço geográfico em que vivem.
\end{abstract}

Palavras-chave: Material de Apoio. Percepção. Estudantes.

\begin{abstract}
Although there are schoolbooks in the libraries as support material for the subjects, there is a need to show students the specifics of the region where they live, since many of these schoolbooks are exogenous. Given the above, the textbook Environmental Chemistry: an introductory and generalist approach, was an attempt to find didactic material that in addition to including subjects of the discipline, presented local examples. Students were interviewed and revealed that the use of this textbook, in addition to being a support tool throughout the course, also played an important role in the process of their professional training and as conscious and active citizens in the geographical space in which they live.
\end{abstract}

Keywords: Support Material. Perception. Students.

\section{Introdução}

A disciplina Química Ambiental é oferecida pelo Departamento de Biologia, no Campus Paulo VI da Universidade Estadual do Maranhão (UEMA), desde 2005. Foi elaborada no sentido de fornecer aos estudantes dos cursos de Licenciatura em Química, Ciências Biológicas e de Licenciatura em Biologia, informações, não somente sobre Química e Meio Ambiente, mas também sobre as relações e interações entre essas áreas do conhecimento.

Por seu caráter multidisciplinar, esse componente curricular incorpora uma ementa abrangente, com temas diversos, que necessitam de livros também diversos, isto é, livros que incluem assuntos de Química, Biologia, Geologia, Ecologia, Geografia, Agronomia, além daqueles da área da Saúde e do Direito. Por essa razão, é necessário o apoio de um livro-texto para auxílio dos estudantes. Por sua relevância, é difícil definir esse material impresso, quanto à função que esse exerce ou deveria exercer em sala de aula.

Embora haja livros na biblioteca da Universidade para a disciplina se tem a necessidade de mostrar aos estudantes as especificidades da região na qual vivem, visto que muitos desses livros apresentam informações de outras regiões do
Brasil ou mesmo de outros países, no caso daqueles traduzidos de Universidades estrangeiras; situação muito comum nas bibliotecas.

Diante do exposto, o livro-texto Química Ambiental: uma abordagem introdutória e generalista (SILVA, 2018) foi uma tentativa de produzir um material didático que incluísse (ou tentasse incluir) a diversidade de assuntos apresentados no programa da referida disciplina. Na elaboração desse material, uma atenção especial foi dedicada em fornecer uma abordagem holística da disciplina Química Ambiental, evidenciando outras áreas do conhecimento, como por exemplo, as Ciências da Saúde, Agrárias, Humanas e Sociais.

A inserção de um livro-texto como uma ferramenta complementar na referida disciplina ajudaria a despertar no estudante a necessidade de leitura mais direcionada para a sua realidade e com exemplos locais. Esse ativismo docente tem como base a construção coletiva e sociocultural da educação, dentro de um processo constante de ensino e aprendizagem.

Independentemente do nível de ensino, não cabem dúvidas acerca do importante papel dos chamados "livros-texto". Como afirma Campanario (2001), esse papel não ocorre apenas no âmbito da construção individual do conhecimento, 
mas também como importante influenciador curricular. É bom destacar que, se através desse livro o professor pretende que o estudante aprenda, é preciso e imprescindível que os significados com que o livro dinamiza, sejam adequados também a realidade da região. Uma Universidade instalada em uma área rural vai requerer como premissa que os livrostextos das disciplinas de seus referidos cursos, tragam assuntos e exemplos que busquem fomentar formas exitosas e sustentáveis de desenvolvimento.

Cabe aqui enfatizar que ao elaborar o seu livro-texto, além de inserir informações locais e vinculadas com a realidade do estudante, o professor deve assegurar uma clara orientação cognitiva para garantir a dialogicidade com o mesmo. $\mathrm{O}$ uso desses livros ainda continua sendo um dos recursos mais utilizados pelo professor, inclusive, servindo como feedback para perceber a afinidade do estudante com a disciplina.

É também, por meio desse que o professor organiza a disciplina que será ministrada, além de poder avaliar seu trabalho pedagógico em sala de aula. Para alguns estudantes universitários esse tipo de material impresso ainda é um elemento de identidade e determinante da sua relação com as disciplinas cursadas.

Fernandes (2004) ao coletar dados para o projeto ressalta que reencontrar um livro-texto é relembrar sua trajetória escolar, dando-lhe um outro sentido, agora emocional, como se fosse uma identidade temporal. Por essa razão, para compreender sua função educacional e sua presença entrelaçada na vida social, é necessário considerar diferentes campos de estudo e privilegiar uma diversidade de fontes de investigação.

A questão sobre o uso de livros-texto, em salas de aula, não deve ser colocada de forma impositiva, mas em termos do uso que se faz desse tipo de material complementar. Por isso, faz-se necessário que os livros-texto sejam concebidos a partir de propostas pedagógicas bem definidas e não como apenas um amontoado de conteúdos. No entanto, cabe aqui enfatizar que mesmo um livro considerado ruim, pode ser um excelente ponto de partida para as discussões desenvolvidas em sala de aula.

E como preconiza Campanario (2001), independente do nível de ensino, não cabem dúvidas acerca do importante papel que desempenham os livros-texto. Pode-se dizer que para muitos professores a seleção desses livros significa sua escolha curricular mais importante, exercendo efeitos poderosos sobre seus enfoques docentes e sobre as estratégias de aprendizagem dos estudantes.

Os livros-texto, segundo Abreu et al. (2005), são convertidos em maior ou menor grau, em referenciais diretos para conteúdos abordados, exemplos utilizados, e atividades dentro e fora da sala de aula. Porém, isso não significa desconsiderar que alterações e sugestões sejam feitas pelos estudantes, em sala de aula, no decorrer da disciplina. Para o referido autor, os textos são reinterpretados com base nas histórias de vida dos professores, suas concepções curriculares e experiências cotidianas no qual se inserem.

Os livros destinados ao ensino universitário permanecem marginais e raramente constituem objetos de pesquisa (SOUZA et al., 2011). O que se percebe nos corredores das universidades é que após o encerramento da disciplina, seu(s) respectivos livros-texto são simplesmente devolvidos para a biblioteca.

Dessa forma, este trabalho apresenta uma análise sobre o uso de livro-texto Química Ambiental: uma abordagem introdutória e generalista (SILVA, 2018) na disciplina Química Ambiental por estudantes dos cursos de Licenciatura em Biologia e Licenciatura em Química da UEMA/Campus Paulo VI. O livro, elaborado pelo professor da disciplina é uma das opções de material didático complementar usado, em sala de aula, pois contempla, de forma resumida e generalista, diversos temas abordados na disciplina.

\section{Desenvolvimento}

\subsection{Metodologia}

A pesquisa se baseia na perspectiva metodológica do estudo de caso em uma abordagem qualitativa. No segundo semestre de 2015 foram aplicados questionários semiestruturados, com perguntas abertas e fechadas com os estudantes dos cursos citados acima, que no primeiro semestre do referido ano haviam feito a disciplina Química Ambiental. Esses questionários foram tabulados e analisados segundo a Análise de Conteúdo, preconizada por Bardin (2011).

\subsection{Relato de Experiência}

No contexto de diversificações e inovações, o uso de livros-texto destinados ao ensino universitário é pouco incentivado nas Instituições de Ensino Superior, IES. Nesses ambientes de aprendizagem, essa ferramenta vem perdendo espaço para apresentações em PowerPoint, que apenas trazem um resumo dos componentes curriculares, sem contextualizálos e/ou detalhá-los.

Souza et al. (2011) entrevistaram docentes contratados entre 1939 a 2002 do Instituto de Química, da Universidade de São Paulo e, observaram diferentes tendências nas metodologias utilizadas com o decorrer do tempo, desde o período em que o ensino de Química permaneceu centrado na figura do professor, passando pela adoção de um único livrotexto até, mais recentemente, o uso de diferentes materiais complementares (apostilas, livros-texto, artigos científicos, textos da internet) como guia para o desenvolvimento de uma determinada disciplina. Dessa forma, estes autores concluíram que mesmo que o professor da disciplina enfatize a relevância desse material didático, deverá também dispor aos estudantes outras possibilidades de bibliografias.

Adotar um único livro-texto, sem dispor de outras referências, impõe ao professor da disciplina, não somente uma limitação de conteúdos, mas também um conjunto 
de procedimentos que condiciona e engessa seu trabalho. Segundo Carneiro et al. (2005), dificilmente, um professor universitário adota apenas um livro-texto, até porque durante o processo de organização, desenvolvimento e avaliação do seu trabalho pedagógico ele utiliza uma variedade de opções, que também incluem os chamados formatos digitais e uso da internet.

Pesquisadores como Zabala (1998) revelam que uma das principais críticas dos livros-texto seria seu tratamento unidirecional da informação; apresentando conteúdos "prontos" e sem possibilidade de questionamento. Com isso, existe uma tendência a não potencializar o contraste entre a sala de aula e a realidade cotidiana; além de favorecer e induzir a aceitação da opinião do autor.

Richaudeau (1979) enfatiza três funções do livro-texto: i) informação e todas as implicações que dessa advêm; ii) estruturação e organização da aprendizagem; iii) orientação em colaboração com outras fontes de conhecimento, que corroboram para o uso de livros-texto como um eficaz suporte para a sua disciplina.

O processo de seleção do(s) livro(s)-texto incube ao professor uma responsabilidade, visto que, geralmente, os estudantes só buscarão o(s) livro(s)-texto escolhidos pelo professor. Esse(s) livro(s), juntamente com a atuação docente, formam uma parceria, quase indissociável, em um processo de ensino peculiar, cujo beneficiário final será sempre: o estudante.

Essa centralidade confere ao livro-texto funções privilegiadas na medida em que é através desse que o professor organiza, desenvolve e avalia seu trabalho pedagógico de sala de aula (CARNEIRO et al., 2005). Apesar de já existirem alguns estudos sobre o uso desse(s) livro(s) nas Universidades, ainda são inexpressivas as pesquisas sobre o acesso e a percepção dos estudantes no que tange a esse material curricular.

A escolha, bem como sua utilização precisa ser fundamentada na competência do professor que, junto com os estudantes, devem fazer do livro um instrumento de ensino e aprendizagem. Assim, para um livro ser considerado "livro-texto", esse precisa ser usado, de forma sistemática, caracterizando-se por ser(em) passível(is) de uso periódico, mas não obrigatoriamente constante. $\mathrm{O}$ que significa dizer que o livro-texto é um suporte, uma ferramenta no processo do aprendizado coletivo. Por essas razões, o livro-texto se dirige, simultaneamente, a dois protagonistas: o professor e o estudante; em um processo participativo de ensino e aprendizagem.

A adoção de livros-texto precisa estar em função da situação coletiva da sala de aula, para que com esse sejam aprendidos conteúdos, valores e atitudes específicos, pois se espera que a aprendizagem não se processe apenas pela leitura das informações que o livro fornece, mas também pela realização das atividades que esse sugere Assim, a qualidade dos conteúdos do livro (informações e atitudes) precisa ser levada em conta nos processos de escolha e adoção do mesmo, bem como, posteriormente, no estabelecimento das formas de uso.

Para Frison et al. (2009), o livro-texto é um instrumento intencionalmente estruturado que se inscreve em um processo de aprendizagem, a fim de melhorar sua eficácia. Por isso sua linguagem deve ser de fácil compreensão, objetiva e sucinta.

Salienta-se que acreditar que um livro-texto é um instrumento de ensino inquestionável é assumir uma visão reducionista. Esse aspecto, segundo Corracini (1999), é perigoso, pois leva à naturalização de tudo aquilo que está escrito no livro-texto, não somente pelo professor, mas consequentemente pelos estudantes, que parecem nem sequer perceber a limitação de sua própria liberdade. Afinal, cede-se ao livro a autoridade de ditar as regras do jogo, de delimitar os conteúdos e as metodologias a serem adotadas em conformidade, é claro, com a ideologia vigente.

Outro aspecto sempre discutido em torno dos livros-texto é que muitos desses não assumem características locais, impedindo uma relação mais direta com o conhecimento e familiarização com termos, conceitos e fatos ressaltados nesses materiais.

Adentrado ao objeto do presente estudo se ressalta que embora o livro Química Ambiental: uma abordagem introdutória e generalista de autoria de Silva (2018) seja usado como livro-texto na disciplina, outros como o de Baird (2008), Rocha et al. (2004) e Spiro e Stigliani (2011), por estarem disponíveis na biblioteca da UEMA, também são usados como referência para os assuntos abordados, em sala de aula, pelo professor/autor do livro.

O livro-texto de Química Ambiental apresenta, além de assuntos relacionados à ementa da disciplina, alguns conteúdos vinculados com a realidade local, usando inclusive exemplos-exercícios associados a essas situações.

\subsection{Resultados e Discussão}

As respostas dos estudantes dos cursos de Licenciatura em Biologia e Licenciatura em Química quanto ao uso do livrotexto são descritas a seguir.

Quando perguntados se a leitura do livro era de fácil compreensão, $88 \%$ dos entrevistados responderam que sim, e justificaram tal fato em função dolivro apresentar uma linguagem próxima ao estudante; similar à usada em sala de aula; com vocabulário acessível e exemplos de situações locais. No entanto, para alguns estudantes (12\%), a linguagem do livro era confusa, em função de erros de digitação e repetições de textos.

Todos os estudantes responderam que o livro era uma ferramenta importante para entender o conteúdo e acompanhar a explicação do professor, assim como para tirar dúvidas e auxiliar no estudo para as provas. Este dado corrobora as afirmações de pesquisadores como Coelho et al. (2015) quando dizem que o livro-texto é de grande importância no processo ensino e aprendizagem; mas que para isso, deve ter 
uma linguagem clara e objetiva, a fim de garantir a máxima compreensão do texto, por parte dos estudantes.

No que diz respeito a maneira como os conteúdos estão organizados no livro, os estudantes avaliaram da seguinte forma: ótima (15\%), boa (59\%), regular (19\%), ruim $(5 \%)$, péssima $(0 \%)$, e $2 \%$ dos entrevistados não responderam. Pesquisadores como Baganha e Garcia (2009) salientam que a estruturação dos conteúdos do livro é importante para ajudar tanto o professor, quanto o estudante, na organização e no aprendizado dos conteúdos escolares.

Quando perguntados sobre a realização da leitura do livro em momentos extraclasse, $78 \%$ responderam que leram o livro em outros momentos e não apenas para realização de atividades; e apontaram fatores como curiosidades, títulos e temáticas atraentes, e utilização em outras disciplinas como principais responsáveis por isso. Aqueles que responderam "não", justificaram isso pela falta de tempo e pela falta de ilustrações explicativas.

Esse resultado foi diferente do obtido por Sillos e Santos (2013), os quais perceberam baixa frequência para essa forma de uso, sugerindo uma subutilização do livro por parte dos $80 \%$ de estudantes que nunca utilizaram o livro com finalidades de leitura de assuntos tratados ou não em sala de aula. Uma explicação para o uso do livro de autoria de Silva (2018) pode ser o fato de apresentar alguns assuntos e situações voltadas para a realidade local.

Sobre a relevância dos conteúdos do livro para a vida profissional e, em sociedade, foi pedido que os estudantes avaliassem por uma nota de 1 a 5 ; sendo 5 a nota que representa maior associação entre o conteúdo para a vida profissional e em sociedade. A maioria (56\%) dos estudantes atribuíram a nota 5 , uma parte $(32 \%)$ a nota 4 e uma minoria (12\%) a nota 3. As notas 1 e 2 não receberam nenhum voto.

Esse feedback reforça a necessidade de os livros-textos apresentarem temas atuais de forma interdisciplinar com os conteúdos básicos da disciplina, além de apresentarem temas que evidenciem a dinâmica da construção do conhecimento científico e possibilitem o desenvolvimento de atitudes e valores relacionados à cidadania (SANTOS; MORTIMER, 2001).

De acordo com Frison et al. (2009), o livro-texto, além de ser um importante recurso de auxílio na preparação e desenvolvimento das aulas dos professores, também é utilizado como facilitador da aprendizagem, sendo um ponto de apoio à prática pedagógica e como material de referência para consulta futuras.

Acerca do incentivo do uso do livro, em sala de aula, por parte do professor: $33 \%$ dos estudantes responderam que a preparação para a prova foi a situação que mais incentivou a leitura, seguido da indicação do professor (26\%). O conteúdo e a temática levaram $22 \%$ dos estudantes a usarem o livro e a curiosidade própria de cada estudante foi responsável por $19 \%$.

Assim como na presente pesquisa, Sillos e Santos (2013), obtiveram como respostas mais escolhidas a indicação do professor e a preparação para a prova. Situação diferente foi observada na pesquisa de Coelho et al (2015) em que houve situações, em que determinados estudantes se interessaram em ler o texto do livro, sem que os professores tivessem solicitado. Dessa forma, quando estes estudantes eram questionados em relação ao assunto, esses já sabiam do que se tratava e respondiam corretamente as indagações feitas pelos professores.

Para o questionamento sobre a contribuição do livro para o aprendizado dos estudantes, $79 \%$ dos entrevistados afirmaram que o material contribuiu muito para seu aprendizado, enquanto $12 \%$ afirmaram ter contribuído pouco e $9 \%$ afirmaram ter contribuído de modo regular. A importância do livro não está somente na transmissão de conhecimentos, auxílio para trabalhos e provas, e melhor explicação do conteúdo debatido; mas também na formação dos estudantes como cidadão político, cultural e científico, tornando-os autores de sua própria história (Coelho et al., 2015).

Para educadores como Lajolo (1996), o livro-texto é um mecanismo de homogeneização dos conceitos e conteúdos, essa organização pelo professor proporciona um melhor acesso ao conteúdo apresentado, facilitando assim a aprendizagem por parte do estudante.

Sobre as dificuldades em utilizar o livro-texto durante a disciplina, a maioria dos estudantes (77\%) afirmaram não terem apresentado nenhuma dificuldade em utilizá-lo, e afirmaram que isso foi em decorrência do conteúdo abordado, em sala de aula, estar de acordo com o conteúdo abordado no livro.

Parte dos estudantes (23\%) afirmaram terem sentido certa dificuldade em alguns capítulos do livro, por estes apresentarem conteúdos técnicos e "difíceis", com vocábulos desconhecidos; solicitando a necessidade de busca de informações complementares. Segundo Frison et al. (2009), é importante que o livro-texto incentive os estudantes a buscarem novas informações, de modo que o mesmo seja utilizado como instrumento de apoio ao professor.

Na pesquisa feita por Sillos e Santos (2013) sobre o uso de livro-texto de Química; chama a atenção o percentual de dificuldades dos estudantes de nível médio, por conta de falta de orientação do professor. A grande maioria dos estudantes atribuíram as dificuldades à linguagem científica e às dificuldades próprias de aprendizagem.

Ao serem questionados se haviam resolvido os exercícios presentes ao final do livro, a maioria dos alunos respondeu que $\operatorname{sim}(71 \%)$ e avaliaram as questões como sendo de dificuldade regular, mas voltadas para o tema da disciplina. Libâneo (2002) enfatiza a importância dos exercícios presentes em um livro didático; para o autor, o aluno utiliza o livro para revisar em casa os conteúdos trabalhados através da resolução de exercícios que reforcem o conhecimento aprendido em sala de aula.

Em relação à penúltima pergunta do questionário, foi 
solicitado aos estudantes que descrevessem aspectos positivos e/ou negativos sobre o livro. Os aspectos positivos citados foram: sincronia entre a explicação do professor e o conteúdo do livro; questões relevantes foram abordadas; linguagem clara; conteúdo abrangente; contextualização dos conteúdos; enquanto os negativos foram: repetições e erros e digitação.

$\mathrm{Na}$ última questão foi solicitado sugestões para melhoria do livro, visando seu melhor aproveitamento na disciplina Química Ambiental. As sugestões dadas foram: correção dos erros de gramática e coesão; incremento de mais figuras no texto, e inclusão de um resumo ao final de cada capítulo.

\section{Conclusão}

Percebeu-se que os estudantes entrevistados consideram o livro-texto utilizado na disciplina Química Ambiental um poderoso aliado no processo de ensino e aprendizagem. Destaca-se, também, que o incentivo e dinamismo do professor para o uso do referido livro contribuiu na identificação desses estudantes com o material didático.

O presente estudo de caso trouxe contribuições que podem ser incrementadas para a próxima edição do livro "Química Ambiental: uma abordagem introdutória e generalista"; além de fornecer subsídios a outros professores que desejam escrever livros-texto para as suas disciplinas.

Enfatiza-se, porém, que o livro-texto não pode ser considerado o único instrumento no processo de ensino e aprendizagem, devendo atuar em conjunto com outros recursos didáticos.

Pode-se inferir pelas respostas dos estudantes entrevistados que a utilização do livro-texto de Química Ambiental, bem como dos recursos disponibilizados por esse, desempenhou um importante papel no processo de formação de cidadãos conscientes e atuantes na sociedade em que vive.

Por fim, com base no que foi levantado nesta pesquisa se conclui que o uso de livro-texto de Química Ambiental, em sala de aula, é uma ferramenta de apoio tanto para o professor da disciplina, quanto para o estudante dos cursos de Licenciatura em Biologia, Licenciatura em Química e áreas afins. No entanto, é necessária a realização de novas pesquisas que tenham os livros-textos como sujeito principal, de modo a gerar novos conhecimentos que possam contribuir com o aperfeiçoamento deste importante recurso didático.

\section{Referências}

ABREU, R.; GOMES, M.M.; LOPES, A.C. Contextualização e tecnologias em livros didáticos de Biologia e Química. Investig. Ensaio Ciênc., v.10, n.3, p.405-417, 2005.

BAGANHA, D.E.; GARCIA, N.M.D. Estudos sobre o uso e o papel do livro didático de ciências no ensino fundamental. ENCONTRO NACIONAL DE PESQUISA EM EDUCAÇÃO EM CIÊNCIAS. 7., Florianópolis, 2009.
BAIRD, C. Química ambiental. Porto Alegre: Bookman, 2008.

BARDIN, L. Análise de Conteúdo. São Paulo: Edições 70, 2011.

CAMPANARIO, J. M. Qué puede hacer um profesor, o um alumno como El tuyo com su libro de texto como este. Uma relacion de actividades poço convencionales. Enseñanza de Ciênc., v.19, n.3, p.351-354, 2001.

CARNEIRO, M.H.S.; SANTOS, W.L.P.; MÓL, G.S. Livro didático inovador e professores: uma tensão a ser vencida. Pesq. Educ. Ciênc., v.7, n.2, p.33-42, 2005. doi: https://doi. org/10.1590/1983-21172005070204.

COELHO, C.K.G. et al. Percepções da relação professor/ livro didático e as formas de utilização de seus recursos na Escola Estadual São Lourenço, Dom Aquino-MT. Rev Monografias Amb., v.14, n.3, p.53-68, 2015. doi: https://doi. org/10.5902/2236130820436.

CORACINI, M.J. O livro didático nos discursos da Lingüística Aplicada e da sala de aula. In: CORACINI, M.J. (Org.). Interpretação, autoria e legitimação do livro didático. São Paulo: Pontes, 1999.

FERNANDES, A.T.C. Livros didáticos em dimensões materiais e simbólicas. Educ. Pesq., v.30, n.3, p.531-545, 2004. doi: https:// doi.org/10.1590/S1517-97022004000300011.

FRISON, M.D. et al. Livro didático como instrumento na construção de propostas de Ensino de Ciências Naturais. In: ENCONTRO NACIONAL DE PESQUISA EM EDUCAÇÃO EM CIÊNCIAS. Florianópolis, 2009.

LAJOLO M. Livro didático: um (quase) manual de usuário. Rev.Em aberto, v.16, n.69, p. 3-11, 1996. doi: https://doi. org/10.24109/2176-6673.emaberto.16i69.2061.

LIBÂNEO, J. C. Didática: velhos e novos tempos. São Paulo: Edição do Autor, 2002.

RICHAUDEAU, F. Conception et production dês manuels scolaires: guide pratique. Unesco, Paris, 1979.

SANTOS, W.L.P.; MORTIMER, E.F. Tomada de decisão para ação social responsável no ensino de ciências. Ciênc. Educ., v.7, n.1, p.95-112, 2001. doi: http://dx.doi.org/10.1590/S151673132001000100007.

ROCHA, J.C.; ROSA, A.H.; CARDOSO, A.A. Introdução à química ambiental. Porto Alegre: Bookman, 2004.

SILlOS, A.E.; SANTOS, W.L.P. Percepções de estudantes do ensino médio sobre o uso de livro didático de Química. In: ENCONTRO NACIONAL DE PESQUISA EM EDUCAÇÃO EM CIÊNCIAS. Águas de Lindóia, SP, 2013.

SILVA, A.C. Química ambiental: uma abordagem introdutória e generalista. São Luís: EdUema, 2018.

SOUZA, K.A.F.D.; MATE, C.H.; PORTO, P.A. História do uso do livro didático universitário: o caso cotidiano do Instituo de Química da Universidade de São Paulo. Ciênc. Educ., v.17, n.4, p.873-886, 2011. doi: http://dx.doi.org/10.1590/S151673132011000400007.

SPIRO T.G.; STIGLIAN, W.M. Química ambiental. São Paulo: Pearson, 2011.

ZABALA A. A prática educativa: como ensinar. Porto Alegre: Artes médicas, 1998. 